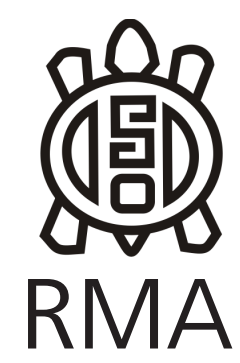

Editorial

\section{Editorial. Patricia Escola y los Cursos de Talla}

\author{
Editorial. Patricia Escola and the Flintknapping Courses
}

Nora Flegenheimer

${ }^{* *}$ CONICET, Área Arqueología y Antropología, Museo de Ciencias Naturales, Municipalidad de Necochea, Argentina. E-mail: norafleg@gmail.com
"En la próxima vida estudio la industria del telgopor"

Pato cargando una pila de piedras para preparar el curso

Como muchos lectores sabrán, nuestro vínculo con Pato estuvo mediado por los "cursos de talla". En 1980, después de una sesión de talla pública con Hugo Nami en las Primeras Jornadas de Tecnología y Tipología Líticas, se acercó una estudiante con cara de "yo quiero eso que recién vi" a consultar por cursos de talla. Era Pato. Un poco más de 10 años después, habiendo vivido su experiencia con Jeff Flenniken en el Flintknapping Course (WSU) se me acercó nuevamente con la propuesta de armar un curso local, argumentaba que había que transmitir lo que habíamos aprendido. Generosa y clara como siempre. Así, en 1994 con Cristina Bayón que trajo al equipo su gran capacidad de trabajo y el apoyo de la UNS, nacieron los Cursos de Talla Experimental y Tecnología Lítica. Fueron en total 14 cursos, dictados entre 1994 y 2015 por los que pasaron unos 200 alumnos, en su gran mayoría graduados de Universidades nacionales. Fueron cursos trashumantes que por muchos años se dictaron con el aval de la UNS aunque en distintos lugares y los 3 últimos fueron cursos avalados por la UNT. Durante los años tuvimos distintos ayudantes y aunque hubo una curricula básica que se mantuvo, fue sufriendo algunas modificaciones.

Las ideas principales que guiaron la enseñanza fueron, que los asistentes se enfrentaran con el hecho de que la talla constituye un proceso técnico pautado y aprendieran sus principios. El objetivo principal fue enseñar a ver el material lítico, con el apoyo en una experiencia práctica. Pato le dedicaba horas de la enseñanza a recorrer a los incipientes talladores y preguntarles ¿dónde encaja esa lasca? ¿dónde diste el golpe? ¿porqué salió así? Podía pasar un largo rato mirando una pieza que traía algún alumno a la consulta, discutiendo qué era, cómo había sido tallada. Estaba enseñando a mirar.

El curso de talla siempre constituyó un espacio de aprendizaje con diversión. Larguísimas jornadas donde se pasaba de la práctica de talla a clases teóricas, observación de colecciones experimentales o videos y a sesiones de actualización bibliográfica o de consulta con los participantes. También era donde las tres, Pato Cristina y yo, nos reuníamos y poníamos al día sobre

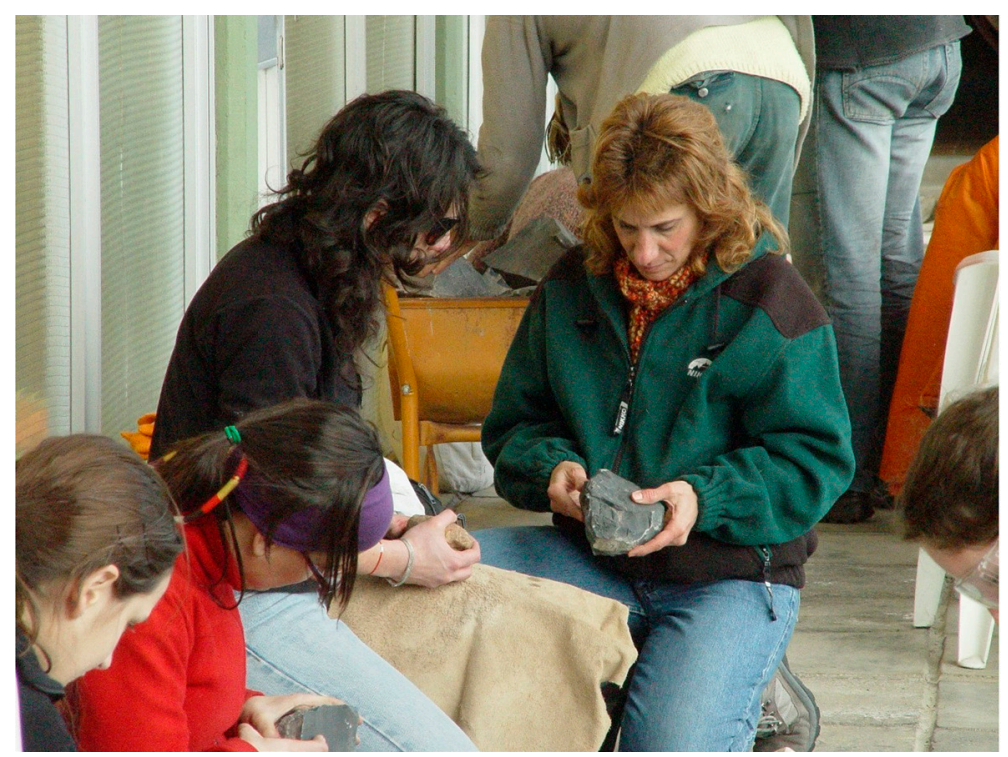

Figura 1. Patricia Escola con alumna durante el XI Curso de Talla Experimental y Tecnología Lítica, año 2007, en dependencias del Área de Arqueología y Antropología de la Municipalidad de Necochea.

Figure 1. Patricia Escola with a student during the XI Course on Experimental Flintknapping and Lithic Technology, 2007, in dependencies of the Archeology and Anthropology Area of the Municipality of Necochea. 
nuestra vida personal y profesional. Era un momento de consulta y reflexión sobre hacia dónde queríamos llevar el trabajo. El espacio de homenaje al curso en el CAELA fue un cierre especial y muy emotivo para lo que fueron años donde cultivamos compañerismo, dedicación y mucho entusiasmo.

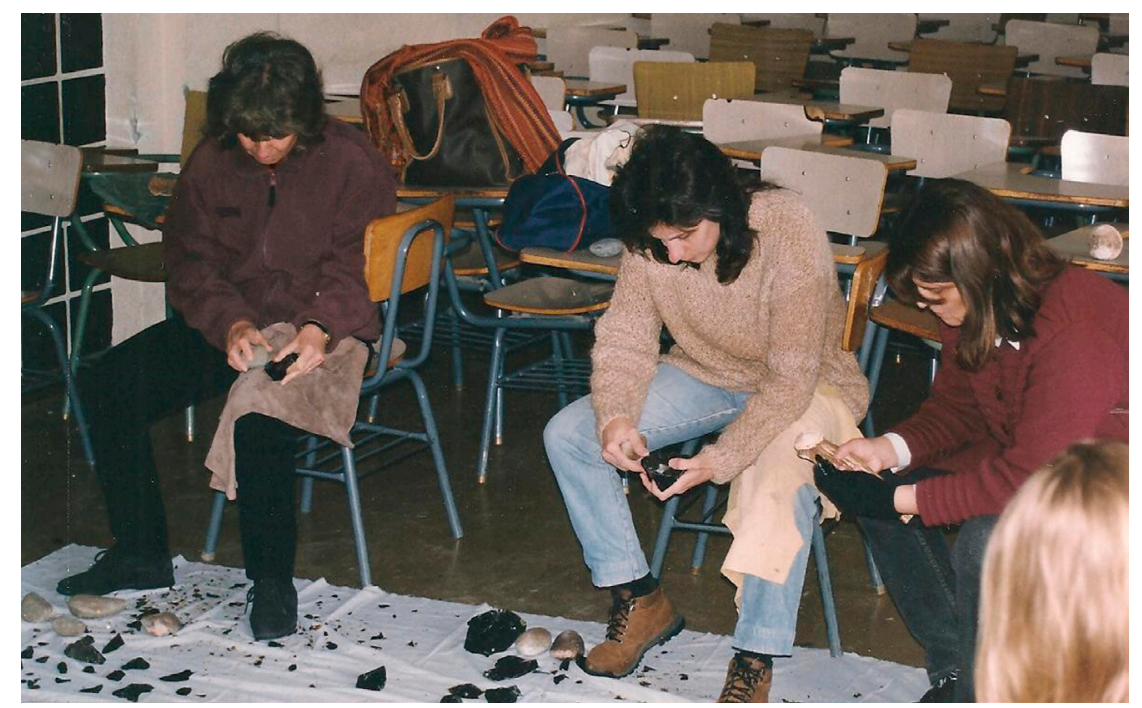

Figura 2. Nora Flegenheimer, Patricia Escola y Cristina Bayón tallando en el VI Curso de Talla Experimental y Tecnología Lítica, año 2000 en dependencias de la Universidad Nacional del Sur (Bahía Blanca, Argentina)

Figure 2. Nora Flegenheimer, Patricia Escola y Cristina Bayón flintknapping during the VI Course on Experimental Flintknapping and Lithic Technology, 2000, in dependencies of the Universidad Nacional del Sur (Bahía Blanca, Argentina)

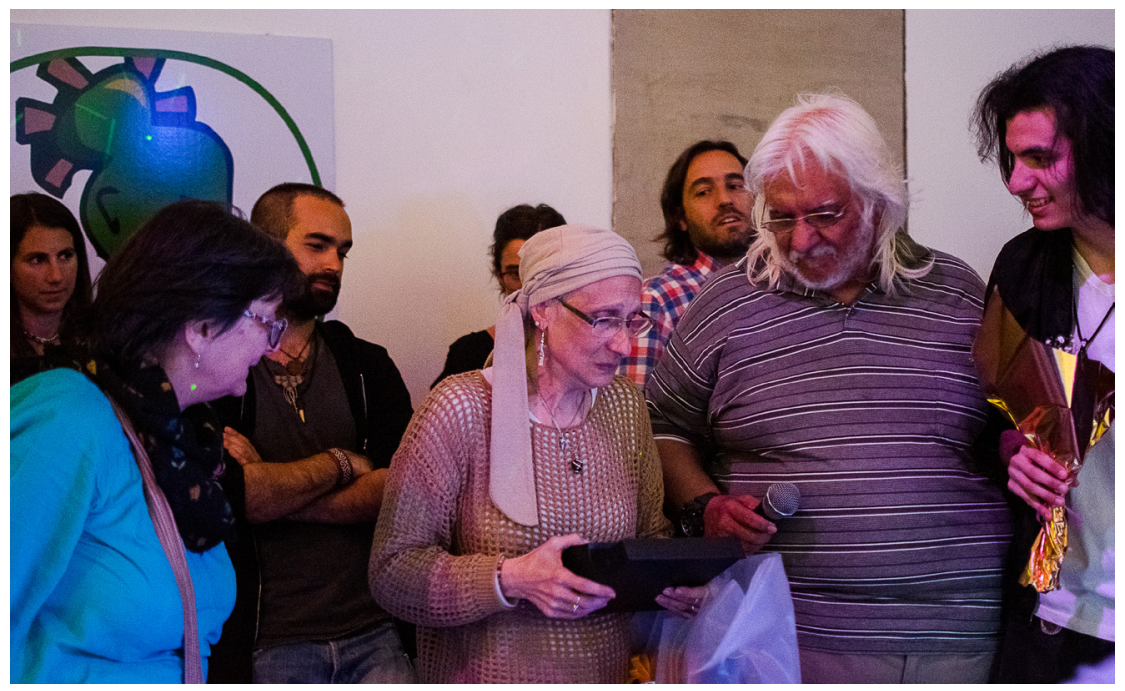

Figura 3. Patricia Escola recibiendo una placa conmemorativa por su rol en los Cursos de Talla durante el 1 CAELA en Córdoba.

Figure 3. Patricia Escola receiving a commemorative plaque for her role in the Flintknapping Courses during the 1 CAELA in Córdoba. 